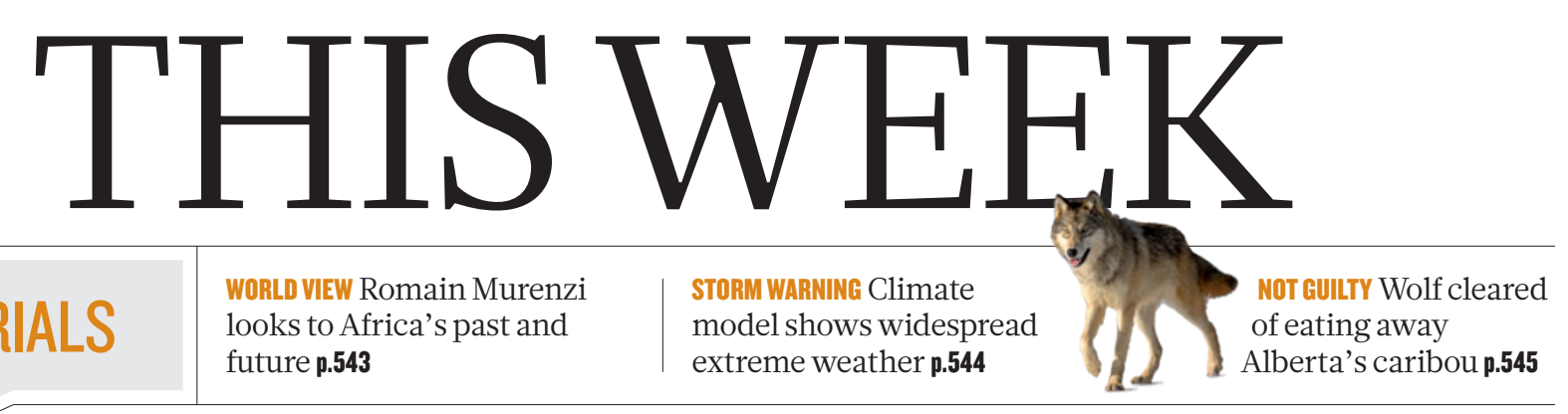

\title{
Shot with its own gun
}

\section{The Intergovernmental Panel on Climate Change must implement changes now to regain lost credibility or it will remain an easy target for critics seeking to score cheap points.}

$\mathrm{F}$ or more than 20 years, the Intergovernmental Panel on Climate Change (IPCC) has performed the essential and time-consuming task of pooling and making publicly accessible the evolving knowledge base gleaned from climate-change research. Its efforts were rewarded in 2007 with the Nobel Peace Prize - not bad for what is basically a voluntary organization staffed by thousands of working scientists. But in the past two years, the IPCC has displayed a talent for manoeuvring itself into embarrassing situations, making itself an easy target for critics and climate sceptics.

The problems began in late 2009, when it was reported that the IPCC's fourth assessment report, published two years earlier, mistakenly claimed that all Himalayan glaciers could melt by 2035 . The subsequent fallout seriously damaged the IPCC's credibility, and was exacerbated by the inept attempts of the group's chairman, Rajendra Pachauri, to contain the crisis. A subsequent review of the organization's governance and policies saw it commit to a number of wide-ranging reforms.

This month, the IPCC is in the crosshairs again. The revelation that a Greenpeace energy analyst helped to write a key chapter in the IPCC's Special Report on Renewable Energy Sources and Climate Change Mitigation, released last month, sparked widespread criticism across the blogosphere. Compared with the glacier faux pas, the latest incident is trivial. But it should remind the IPCC that its recently reworked policies and procedures need to be implemented, visibly and quickly.

In response to the glacier blunder, the IPCC pledged greater caution in the processes it uses to select scientific experts and to evaluate grey literature, and to make sure that (unpaid) work for the panel does not clash with interests arising from the professional affiliations of its staff and contributing authors (see Nature 473, 261; 2011). But it has failed to make clear when this new conflict-of-interest policy will come into effect and whom it will cover. It needs to do so - and fast.

This is the only way that the organization can counter recurring claims that it is less policy-neutral than its mandate from the United Nations obliges it to be. In particular, it needs to make clear the position for the working groups on climate-change impacts and adaptation (the science group adopted a rigid conflict-of-interest policy last year). Pachauri is on record as saying that the new conflict-of-interest policy will not apply retrospectively to the hundreds of authors already selected for the IPCC's fifth assessment report, due in 2014. This is unacceptable. He should make it a priority to ensure that the rules cover everyone involved - including himself.

Claims in the blogosphere that Greenpeace 'dictated' the IPCC's renewable-energy report are vastly exaggerated. In fact, the Greenpeace writer was one of six authors of a peer-reviewed paper that examined an extreme scenario of favourable economic conditions that allowed the maximum possible take-up of renewable energy sources by 2050 . Although the scenario is optimistic - and no doubt in line

with the agenda at Greenpeace HQ - its inclusion is entirely justified. How else could the report answer the question of how much renewable energy would be possible under different economic assumptions?

Greenpeace probably fights just as hard to promote its values as the fossil-fuel lobby does for its own interests. But in principle there is

"The IPCC

should reconsider how it frames its findings." nothing wrong with asking experts from either side to contribute to the IPCC's reports - even though the reports represent a supposedly value-free extension of academic science. But by neglecting to ask the Greenpeace-linked author of the extreme scenario in question to disclose his affiliation and possible conflicts of interest openly and formally, the IPCC recklessly exposed itself to its critics.

The IPCC's vulnerability to such attacks should also prompt it to reconsider how it frames its findings. Journalists and critics alike gravitate towards extreme claims. So when the IPCC's press material for the May report prominently pushed the idea that renewables could provide "close to $80 \%$ " of the world's energy needs by 2050 , it was no surprise that it was this figure that made headlines - and made waves. The IPCC would have saved itself a lot of trouble and some unwarranted criticism had it made the origins of this scenario explicit.

There is no escaping the fact that the IPCC operates in a latently hostile environment. Its critics are vocal, frequently melodramatic and unlikely to surrender the limelight any time soon. The IPCC has to stop handing them ammunition on a plate.

\section{Made in Japan}

\section{A new university on an island outpost looks set to succeed against the odds.}

J apan has long struggled with an ambition to be international. In 1989, it gave the world the Human Frontier Science Program (HFSP). This year, it will give itself the Okinawa Institute of Science and Technology (OIST), a little piece of the rest of the world in Japan, expected to be accredited as a university in November.

Nobel laureate Torsten Wiesel, secretary-general of the HFSP from 2000 to 2009 and now co-chair of the OIST's board, got it right when he said that both initiatives show the wisdom of the Japanese government: in trying to build bridges, to embrace and be embraced by the international community.

The 1989 bridge-building exercise, coming at the tail end of several decades of economic boom, was a token gesture. In terms of the internationalization of Japan, little changed, and there was little pressure 